\title{
A importância da mediação comunicativa da informação na prática bibliotecária
}

\author{
Jetur Lima de Castro \\ Mestrando; Universidade Federal do Pará, Belém, PA, Brasil; \\ jetur.er@gmail.com \\ Luiz Eduardo Ferreira da Silva \\ Doutor; Universidade Federal da Paraíba, João Pessoa, PB, Brasil; \\ luizeduardo.ufpb@gmail.com \\ Alessandra Nunes de Oliveira \\ Mestranda; Universidade Federal do Pará, Belém, PA, Brasil; \\ alessandranunesoliveira@gmail.com
}

\begin{abstract}
Resumo: Considerando que ações comunicativas possibilitam práticas relacionais que percorrem para além da transferência de conhecimento nas atividades bibliotecárias, objetiva-se analisar a importância da Mediação da Informação como ação de libertação coletiva na prática dos bibliotecários. Para isso, buscou-se um estudo teórico, cujo desenvolvimento se baseou na idéia de ação comunicativa de Jurgen Habermas, a partir da autorreflexão. Assim, notase que, na prática bibliotecária a Mediação da Informação, prevalece na racionalidade instrumental da técnica e, por esta razão precisa, portanto, percorrer o plano de ações comunicativas e emancipadas. Embora o assunto estudado seja explorado pela literatura, deve-se considerar que seus fundamentos teóricos e práticos ainda não foram projetados criticamente, especialmente ao avaliarem as "novas" relações de debate em seu ambiente e um novo significado nas práticas bibliotecárias.
\end{abstract}

Palavras-chave: Ação Comunicativa. Razão Instrumental. Emancipação. Mediação. Bibliotecário.

\section{Introdução}

No panorama histórico da informação, a CI como conhecimento veio a se consolidar enquanto um campo científico no final do século $\mathrm{XX}$, especialmente pela explosão da informação registrada pela diversidade de saberes derivados de atividades que constituem a organização e a produção do conhecimento em centros de documentação e bibliotecas. Por esta razão, essa área, tem se ampliado por meio das necessidades atuais de informação em termos de 
disseminação e uso, mas notadamente prestando acesso a certos aspectos da informação na perspectiva global.

Diante dos aspectos apresentados, se analisa a partir de uma perspectiva teórica que o conhecimento biblioteconômico, vem a ser configurado para além do resultado do processo de organização e transferência do conhecimento. Dado que a transferência do conhecimento estar associada a uma compreensão reduzida das formas de comunicação as quais no paradigma informacional são concernentes a um emissor, receptor, mensagem e processo de canal por meio do qual a mensagem é codificada e enviada.

Partindo da premissa de que a Mediação de Informação excede a estrutura lógica dos meios sociotécnicos (conhecimento técnico) e de que, as ações comunicativas possibilitam caminhos de práticas relacionais na mediação que percorre além da transferência de conhecimento nas atividades bibliotecárias, neste texto, apresenta-se a importância da Mediação da Informação como uma ação coletiva emancipatória na prática bibliotecária. Uma discussão importante a qual, a Mediação da Informação é pensada como um canal coletivo de ação emancipatória da informação na qual proporciona um espaço de compreensão dos problemas que desafiam as práticas de mediação bibliotecária.

Neste contexto, a base metodológica do estudo, vem a constituir-se como teórica partindo da visão de que se "[...] manifesta como uma hipótese eterna que mantém viva a necessidade de pesquisa, tornando a ciência um edifício em construção permanente." (KÖCHE,1997, p. 99). Além disso, conta com a crítica interpretativa, cujo desenvolvimento baseou-se no pensamento de Jurguen Habermas sobre a ação comunicativa, maiormente, na caracterização da autorreflexão a qual vem assegurar a intersubjetividade de uma “[...] compreensão entre indivíduos, capaz de orientar a ação (horizontalmente, em vista da interpretação de culturas estranhas, e verticalmente, tendo em vista a apropriação de tradições próprias)." (HABERMAS, 1987, p. 212).

Noutras palavras a autorreflexão ${ }^{1}$ acompanha $\mathrm{o}$ entendimento intersubjetivo dos sujeitos que apresentam ações discursivas de solidariedade possibilitando a compreensão de um espaço emancipatório. Consequentemente 
um outro aspecto a ser abordado neste texto, leva em consideração a necessidade de estabelecer conceitos teóricos por meio da prática reflexiva, para que a Mediação da Informação não seja reduzida em informação, usuário e mediador de um modelo pragmático da ciência.

Se esclarece, portanto, que a Mediação da Informação se fundamenta na ação emancipatório a qual constitui-se a partir de vínculos sociais, visões histórico-hermenêuticas, atividades de comunicação e sua diversidade na prática bibliotecária. E entende-se, desta forma, que a Mediação da Informação bibliotecária necessita de questionamentos teóricos, a fim de consolidar com um olhar crítico "novas" relações possíveis de debate em torno do seu núcleo teórico-prático, de modo que os reflexos das ações comunicativas possam transcender seus elos políticos fundados na razão instrumental (ideologia da técnica), vindo a considerar uma abordagem relacional, principalmente, na produção de ações coletivas emancipatórias no ambiente das bibliotecas e, por fim, práticas que ressignificam a mediação.

\section{Fios e rastros da mediação da informação}

Ao explicar a Mediação da Informação, podemos observar algo que é constantemente citada na literatura da CI e na Biblioteconomia as quais buscam energias para compreender os atuais processos e práticas informacionais no social, a partir de processos organizacionais, meios e aplicações da tecnologia da informação como o armazenamento e recuperação.

Tendo em vista esses aspectos, a concepção de Mediação da Informação na atividade bibliotecária, por exemplo, tem sofrido inferências das chamadas ciências empírico-analíticas, as quais do ponto de vista de Habermas (1980) fundam-se em regras técnicas baseadas no saber empírico. Em outras palavras, “[...] elas implicam em cada caso, prognósticos condicionais quanto a acontecimentos observáveis, físicos ou sociais [...]” (HABERMAS, 1980, p. $320)$.

Por isso a teoria crítica de Habermas pode ajudar-nos a esclarecer porque a compreensão de Mediação da Informação surge de um ponto de vista técnico na qual está sustentada pelo modelo teórico e paradigmático da Teoria 
Matemática da Comunicação (TMC), que a princípio, contribuiu na gênese científica de informação designando, tão-somente, questões objetivas (formas físicas de transferência de informação) sobre a emissão de informações.

Como pode ser visto por Araújo ao afirmar que:

Shannon e Weaver reconhecem que as questões relativas à comunicação envolvem três níveis de problemas. O primeiro trata dos problemas técnicos, relativos ao transporte físico da materialidade que compõe a informação (como, por exemplo, o volume do som numa conversa ou a qualidade da impressão em um papel). O segundo nível se refere aos problemas semânticos, isto é, se relaciona com a atribuição de significado. Enquanto o primeiro nível envolve apenas uma operação mecânica (reconhecer as letras num papel, captar os sons de uma fala), o segundo se relaciona a uma operação mental específica, a de depreender, de determinada materialidade (sonora, visual, etc.), um sentido, que pode se dar de maneira conotativa ou denotativa, literal ou irônica, metafórica, etc. O terceiro nível é o pragmático, relaciona-se com a eficácia. Quem emite informações a outrem deseja, de algum modo, provocar um comportamento, causar alguma reação (convencer alguém a comprar um produto, eleger um candidato, pedir um favor, etc). (ARAÚJO, 2009, p. 193).

Nesse contexto, é certo que o paradigma da informação de Shannon/Weaver, teoricamente, levou à reforma da informação e se tornou mais perto de tecnologias baseadas no conhecimento nas ciências exatas e naturais, tais como a física, a química e a biologia que se despontam na transformação de materiais com o propósito de produzir objetos tangíveis, reais e concretos destinados ao consumo.

Ainda assim a intenção de Shannon estaria baseada na transmissão de mensagens, uma conexão probabilística traduzida em traços mecânicos de informações na qual se encontra formatada na ideia de fluxos de informações em sistemas de informação. Como apresentado por Araújo (2009, p. 149) Shannon e Weaver "[...] rejeitam a subjetividade como parte da informação, permitindo assim uma aproximação dela como um fenômeno objetivo, independente dos sujeitos que é, portanto, susceptível de ser estudado cientificamente.".

Por outro lado, cabe ressalvar que nas trajetórias e vivências interpretativas, deste estudo, a Mediação da Informação vem a constituir-se uma ação coletiva emancipatória. Também, entendemos que, nas áreas de 
conhecimento em que o conceito é validado, no caso da CI e da Biblioteconomia, busca-se promover estudos teóricos mais aprofundados para avaliar as ações resultantes das práticas emancipatórias nas investigações sobre a Mediação de Informação.

Na visão de Almeida Júnior (2009) o atual e antigo modelo conceitual da literatura da CI sobre a Mediação da Informação é visto como uma base para a compreensão, assimilação e apreensão, necessária para as práticas de informação. Ao mesmo tempo o autor vem demonstrar que "[...] a mediação de informação não possuía um conceito específico que respondesse a questões levantadas em projetos de pesquisa destinados a mediar a informação como objeto." (ALMEIDA JÚNIOR, 2009, p. 91).

Do ponto de vista de Almeida (2008) o contexto social das interações comunicacionais na história humana pouco se modificou até o século $\mathrm{XV}$, quando predominaram as interações face a face. Dentro destas interações teve alternâncias e arranjos de significados das diversas formas de informação na sociedade. Para o autor, essa ocorrência é vista pelos fatores sociotécnicos que surgiram em meio a transformação do conteúdo e os meios tecnológicos. Assevera, ainda, Almeida que:

O intercâmbio de informação e conteúdo simbólico sofre uma profunda mudança com as inovações tecnológicas (imprensa e, posteriormente, meios eletrônicos): que as interações face a face cedam cada vez mais espaço para as interações mediadas e as "interações quase mediadas" as relações que as pessoas estabelecem com os conteúdos dos meios. (ALMEIDA, 2008, p. 13).

Desta maneira, as interações estabelecidas com os meios tecnológicos vieram amplificar as representações de mediação, mas também, se tornariam submersas as mediações representadas por regimes de informação as quais registram as formas mediadas de ação ${ }^{2}$, nas quais são produzidas na ação comportamental do indivíduo a partir dos meios que se comunicam.

Por outras palavras à ação dos meios tornou-se problemática na Mediação da Informação nas práticas bibliotecárias, a exemplo de como o bibliotecário pode estar à frente da questão de alcance entre a informação e os usuários nas bibliotecas. De como, então, seria a perspectiva referente ao mediador? Qual seriam os pressupostos da mediação "ser" uma ação coletiva 
emancipatória? Visto as formas mediadas de ação, implicam uma postura do "ser do bibliotecário" com o ambiente inserido e seu contexto.

Do ponto de vista de Almeida Júnior (2009, p. 92), a Mediação da Informação na prática bibliotecária, constituir-se-ia:

[...] toda a ação de interferência - realizada pelo profissional da informação -, direta ou indireta; consciente ou inconsciente; singular ou plural; individual ou coletiva; que propicia a apropriação de informação que satisfaça, plena ou parcialmente, uma necessidade informacional. [...] a mediação não estaria restrita apenas a atividades relacionadas diretamente ao público atendido, mas em todas as ações do profissional bibliotecário, em todo fazer desse profissional.

Na compreensão das chamadas ciências empírico-analiticas, no que se refere a Mediação da Informação, disporia ela, tão-somente, vinculada ao serviço de informação e a referência da biblioteca, especificamente nos espaços das artes que visam o serviço dos usuários nas bibliotecas.

Consequentemente, cria-se uma concepção de que a informação é o processo da conjuntura do profissional da informação, por outro lado, entendese também que a apropriação da informação requer emancipação por não está diretamente relacionada à questão profissional e ao atendimento ao público (formas não mediadas de informação).

Gonzalez de Gomez (1993), ao explicitar o conceito de transferência de informação $^{3}$, pensa a Mediação da Informação na dimensão do paradigma informacional. De acordo com a Especialista o que caracteriza a transferência de informação é o conjunto de ações através dos quais grupos sociais e as próprias instituições organizam e implementam a comunicação de informações. Embora ao tencionar o fundamento teórico exposto por Gonzalez de Gomez (1993), reflete-se em relação a práticas informacionais que possam culminar no projeto de emancipação pelo viés das razões comunicativas as quais estão presentes ou não nas ações do profissional da informação.

Um aspecto de caráter prático pode ser considerado, a título de exemplo, avaliamos a mediação entre bibliotecário e os usuários da biblioteca numa “[...] concepção de informação que os desloque da categoria de mero receptor, colocando-os como atores centrais do processo de apropriação da informação 
[...]" (ALMEIDA JÚNIOR, 2009, p. 97). Assim também, construir-se-ia a ação emancipatória, a qual se institui na libertação da razão positiva pela ação comunicativa $^{4}$ que de acordo com Habermas (1999), encontra-se no paradigma legitimador do discurso e da ação, em que acordos se constituem entre os sujeitos a partir do processo da ampliação argumentativa voltada a uma necessidade informacional.

Além disso, por apresentar inferências as questões informacionais a partir do modelo teórico, é que tentamos refletir a Mediação da Informação por intermédio da autorreflexão, sendo uma "[...] via de compreensão, que exerce seu potencial gerativo de entendimento num processo de interação social coordenado de forma cooperativa. " (STIELTJES, 2001, p. 62).

Em outras palavras, a autorreflexão atravessa o lugar da mediação do bibliotecário podendo ser característica na prática informacional emancipatória em bibliotecas, pautada na reflexão sobre as construções dos níveis que tratam da informação técnica, explicitando o contexto relacional e discursivo dos sujeitos nesses espaços, tornando-se um “[...] lugar de sentidos e de relações; lugar não apenas onde os sujeitos dizem, mas também assumem papéis [...]" (FRANÇA, 2001, p. 16).

O paradigma informacional Shannoniano restrito à emancipação social norteia as organizações por meio da transferência de informação, principalmente pelas novas tecnologias da informação. Conforme é sublinhado por Habermas, ao dizer que:

Hoje, a dominação eterniza-se e amplia-se não só mediante a tecnologia, mas como tecnologia; e esta proporciona a grande legitimação ao poder político expansivo, que assume em si todas as esferas da cultura. Neste universo, a tecnologia proporciona igualmente a grande racionalização da falta de liberdade do homem e demonstra a impossibilidade 'técnica' de ser autónomo, de determinar pessoalmente a sua vida. (HABERMAS, 2009, p. 49).

Conforme já foi constatado, nos parece, portanto, que a comunicação da informação deixou certas fissuras, principalmente em se obter a informação, à medida que esse fator se tornou desigual e impossibilitou a participação efetiva dos sujeitos nas atividades e práticas de apreensão da informação. A noção de mediação parece, portanto, designar, neste caso, as “[...] operações, assim como 
os seus efeitos - de tecnicização do processo de comunicação (mediação técnica)." (DAVALON, 2003, p. 9).

A Teoria Matemática da Comunicação (TMC) está, deste modo, correlacionada com a noção da mediação e dos efeitos da "tecnificação" e enfeites tecnonormativos, já que se apresenta sob um modelo posto a reduzir as incertezas de troca de mensagens.

De acordo com Habermas (2009, p. 31), esses processos:

[...] formam sob as condições da comunicação linguística, mas nada têm em comum com as regras comunicativas da interação. Nos imperativos condicionados, a que se segue a ação instrumental e que, por seu lado, resultam do domínio experiencial da acção instrumental, só entra a causalidade da natureza, e não a causalidade do destino.

Na prática a relação comunicativa pode ser instrumentalizada, pois há, portanto, uma interação e ação isolada do lado do sistema que, deste modo, permanecem condicionadas às suas próprias experiências empíricas. Neste contexto, Habermas (1981) vem mostrar que a ação comunicativa tem um papel importante na linguagem e na interação humana, visto que o entendimento mútuo entre os sujeitos significará um diálogo crítico. Esta relação será perceptível quando haver racionalidade intersubjetiva dos sujeitos a partir das ações discursivas.

Assim, se faz necessário que a Mediação da Informação considere a maneira que ocorre a ação intersubjetiva na prática bibliotecária com os usuários da biblioteca. O (não) diálogo, o eixo intencional e a regulação no processo de informação ${ }^{5}$, reduz o conhecimento e a diversidade do contexto informacional, por meio da ferramenta operacional sistêmica que mede a cálculos matemáticos e divide os sujeitos a unidades métricas nas bibliotecas. Essa deve ser (res)truturada, em razão de (in)visibilizar a compreensão das múltiplas formas mediadas de ação dos sujeitos nas bibliotecas.

Assim, ao trabalhar coletivamente para fornecer informações em bibliotecas, o bibliotecário utiliza-se dos princípios da ação comunicativa a partir de uma perspectiva crítica. De outra maneira, ele contribui com sua capacidade intersubjetiva para compreender determinados contextos sociais nas 
bibliotecas, engajando-se em um diálogo colaborativo e participando das necessidades de informação dos usuários.

As reflexões de Almeida (2009) indicam que, a função do mediador está na ação coletiva, uma vez que permite aos usuários acessar livremente as informações e liberá-las de práticas técnicas. As mediações comunicativas são, portanto, conexões estabelecidas por ações e causas sociais (individual/coletiva).

Como descrito por Almeida no contexto profissional atual:

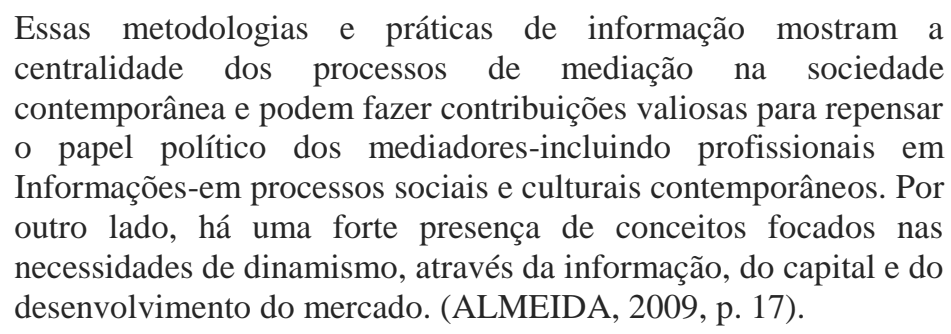

Ainda na visão de Almeida (2009), algumas práticas são questionadas nos processos de Mediação da Informação e, assim, sublinham a relação, mesmo que seja explorada, corroboram por um aspecto objetivo na apreensão de informação em que os sujeitos estão.

Desta maneira, a ação comunicativa desses sujeitos, não se fundamenta simplesmente em normas morais ou ideais políticos. Esta teria, “[...] adicionalmente, um sentido descritivo, identificando na própria prática cotidiana a voz persistente da razão comunicativa, mesmo em situações em que essa está subjugada, distorcida e desfigurada" (HABERMAS, 1989, p. 9).

Conforme Habermas (1989) o que importa é a prática da argumentação, as "pretensões de legitimidade", das quais os sujeitos são guiados, as pretensões são enfatizadas e questionadas. A ideia aqui seria pensar os atos ilocutórios de bibliotecários e usuários que interagem racionalmente com o propósito de se descobrirem como sujeitos reais na biblioteca. Por outro lado, a reflexão com relação a mediação na prática da bibliotecária permite considerar um “[...] novo hábito dialético e reflexivo no contexto social pela qual torna os sujeitos da biblioteca autônomos às regras técnicas baseadas no conhecimento empírico" (HABERMAS, 2009, p. 57). 
De outra forma, essa relação pode ser qualificada por intermédio da ação comunicativa, a qual propicia possibilidades de comunicação, dialogando de forma recíproca como sujeitos, tratando-se de uma ação coletiva emancipatória e não mais de uma mediação condicionada a artefatos técnicos do processo regimentar de informação, de outra maneira, que não seja o modo “[...] informacional dominante em uma formação social, o qual define quem são os sujeitos, as organizações, as regras e as autoridades informacionais." (GONZALEZ DE GOMEZ, 2012, p. 43).

\section{0 problema da mediação bibliotecária}

Qual é o problema da mediação na prática bibliotecária que torna ausente a emancipação? "Em sua história, a Biblioteconomia isolou-se da sociedade, encastelando-se em seu espaço, empregando técnicas criadas para atender e responder necessidades oriundas de suas próprias entranhas." (ALMEIDA JUNIOR, 2015, p. 133).

Em relação à prática da mediação no saber-fazer e a ação técnica e instrumental, é essencial que sejam dispostas pela ação comunicativa a qual conduz práticas discursivas e uso de habilidades linguísticas na interação dos sujeitos na biblioteca.

Quanto a ação técnica e instrumental Habermas (2009, p. 101) esclarece que se trata de um "[...] layout cientificamente racionalizado aos objetivos dos processos; refere-se assim ao sistema em que a investigação e a técnica se encontram com a economia e a administração e são por elas retro-alimentadas.".

Por outro lado, o saber técnico é "um tal saber reflexivo, que se sintetiza na consciência hermenêutica, distingue-se evidentemente do saber-fazer que caracteriza a compreensão e o próprio discurso disciplinado" (HABERMAS, 2009, p. 302).

Habermas (1987) entende que a racionalidade técnica pode ser decifrada pela compreensão hermenêutica dos sujeitos situados.

Que explicações causais (as quais se apóiam sobre um saber empírico-analítico) possam ser em princípio convertidas em um saber tecnicamente aproveitável, e explicações narrativas (as quais se apóiam em um saber hermenêutico) em um saber prático, 
permaneceria um fenômeno apenas curioso, caso não pudéssemos explicar e fundamentar esta circunstância como transcendentalmente necessária, a partir da inserção condicional do saber teórico em uma conexão universal de interesse (HABERMAS, 1987, p. 345).

Como se pode observar, a Mediação da Informação aperfeiçoa as habilidades dos próprios bibliotecários pelo saber-fazer. De acordo com Silva (2013) o "saber-fazer” se reserva nas técnicas da Biblioteconomia e nas ações práticas do bibliotecário, criando assim, uma relação ativa entre o conhecimento prático, as formas funcionais instrumentais e comunicativas nas bibliotecas.

$\mathrm{Na}$ Figura 1, analisamos a Racionalidade do conhecimento, a Racionalidade instrumental com uma relação entre meios e fins, a técnica como um conhecimento ideológico do método e do processo de produção do conhecimento, e, por fim ao saber-fazer como fornecedor de um conhecimento prático para usos dos processos da técnica.

Figura 1- Relações da racionalidade instrumental (técnica) e o (saber-fazer)

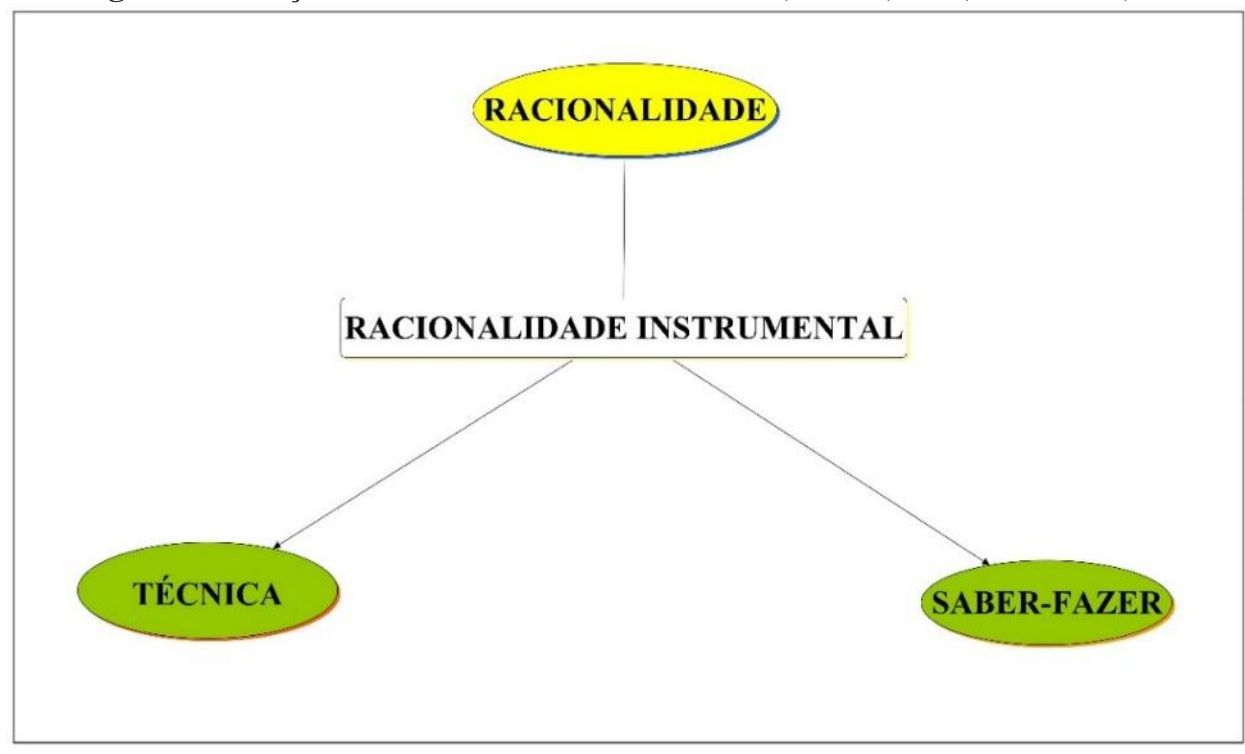

Fonte: Dados da pesquisa (2018).

Sabe-se que a ação instrumental (técnica) está diretamente ligada a formas práticas do saber-fazer, que não difere da configuração atual das atividades bibliotecárias, como exemplo das práticas de representação, gerenciamento de informações e ferramentas tecnológicas aplicadas em bibliotecas. 
Na Figura 2 apresenta-se o desafio de analisar como a correlação entre a racionalidade instrumental (técnica) que explora a compreensão de ação comunicativa em um ato emancipatório entre os sujeitos bibliotecários e usuários.

Figura 2- Relações de racionalidade técnica, mediação emancipatória entre sujeitos.

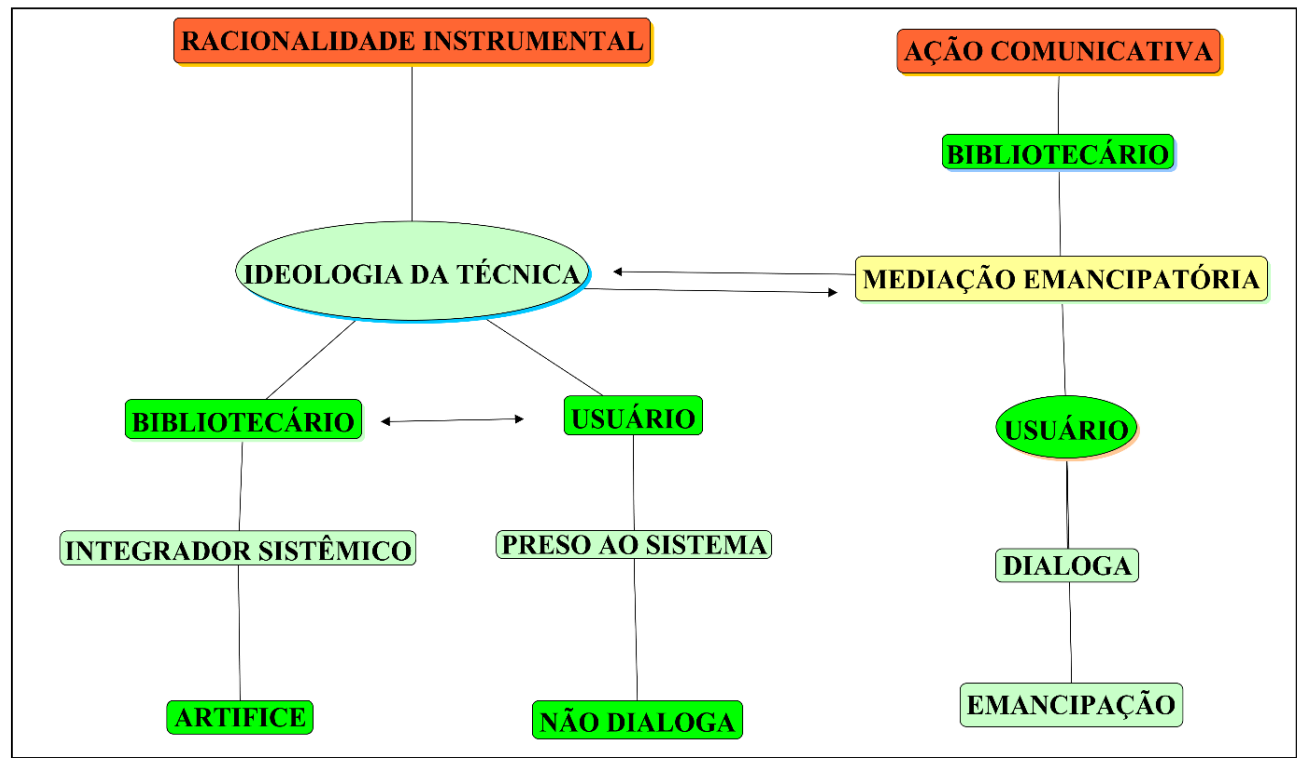

Fonte: Castro, Silva e Oliveira (2018).

A Figura 2 destaca a ideologia da técnica nas bibliotecas em que é sistematicamente classificada como uma integração de funções técnicas institucionais que não interage com os usuários. Examinando o interesse predominante na estrutura do sistema de bibliotecas e o fato de ser um ato revelador, atua como mecanismo institucional.

Como se pode observar, o diálogo dos sujeitos bibliotecário-usuário é entorpecido pela estruturação do sistema, entende-se que, seu confinamento permanece na dependência de uma estrutura coercitiva, sobretudo, nos processos instrumentais de classificação, catalogação, pelas quais deixam os bibliotecários e os usuários em uma dependência rigorosa, cartesiana e funcionalista.

De fato, o recurso pragmático insere os sujeitos em uma estrutura coercitiva, pois a razão técnica prejudica o estado de ação dos bibliotecários e usuários, isenta-os de sua subjetividade e os conduz a uma pragmática instrumental (técnica) a partir do armazenamento de informação, alimentado pelo sistema de controle. Se considerarmos o caráter técnico na prática 
bibliotecária como mediação, poderemos rastrear os pressupostos da objetividade das ciências positivistas e à sua natureza instrumental (técnica).

Em termos de diálogo, deve-se compreender que fluxos (mediações) das práticas bibliotecárias são previstos pelas suas estruturas e fundações, na direção de serem ressignificadas a partir da "[...] disposição dos sujeitos capazes de falar e de agir, de buscar um entendimento acerca do mundo, orientando-se pelas pretensões de validade que estão assentadas no reconhecimento intersubjetivo." (HABERMAS, 1998, p. 437).

Por esse ângulo, a ação comunicativa nos sujeitos da biblioteca provoca o diálogo mútuo, influenciando, diretamente a Mediação da Informação e permitindo-lhes transcender o modelo instrumental que torna impossível a sua própria emancipação. E, a partir disso, a Mediação da Informação, de forma emancipatória, fora das aporias da técnica, no sentido de que os sujeitos venham alcançar a intersubjetividade, a compreensão comunicacional e a troca de informação, apresentando-se numa "ação coletiva".

Neste universo podemos compreender a mediação como ação emancipatória coletiva, diante de suas questões pragmáticas, questiona-se as "falhas" nas ações técnicas, organização, recuperação, disseminação da informação como um todo e de seu desenvolvimento com as tecnologias necessárias que, nesse sentido, devem ser observadas constantemente na interatividade com os sujeitos que buscam informações nas bibliotecas.

Por essa razão, a emergência de questões teóricas por intermédio da interpretação dos sujeitos, seria efetivamente uma estratégia no sentido de uma reconstrução, uma maneira de pensar na teoria e na prática essa relação pela dialética. Em razão de que muitas das vezes se concebe a prática como uma aplicação da teoria, como uma consequência; às vezes ao contrário, como devendo inspirar a teoria, como sendo ela própria criadora com relação a uma forma futura de teoria. Defende-se, neste caso, a criação de conjuntos dialógicos que permitam estabelecer ações discursivas para superar as barreiras da cientificidade e fortalecer a autonomia dos sujeitos para falar por si.

A Figura 3 esboça a rede de etapas construtivas que os bibliotecários e usuários devem estabelecer comunicativamente. 
Figura 3 - A compreensão comunicativa entre atores

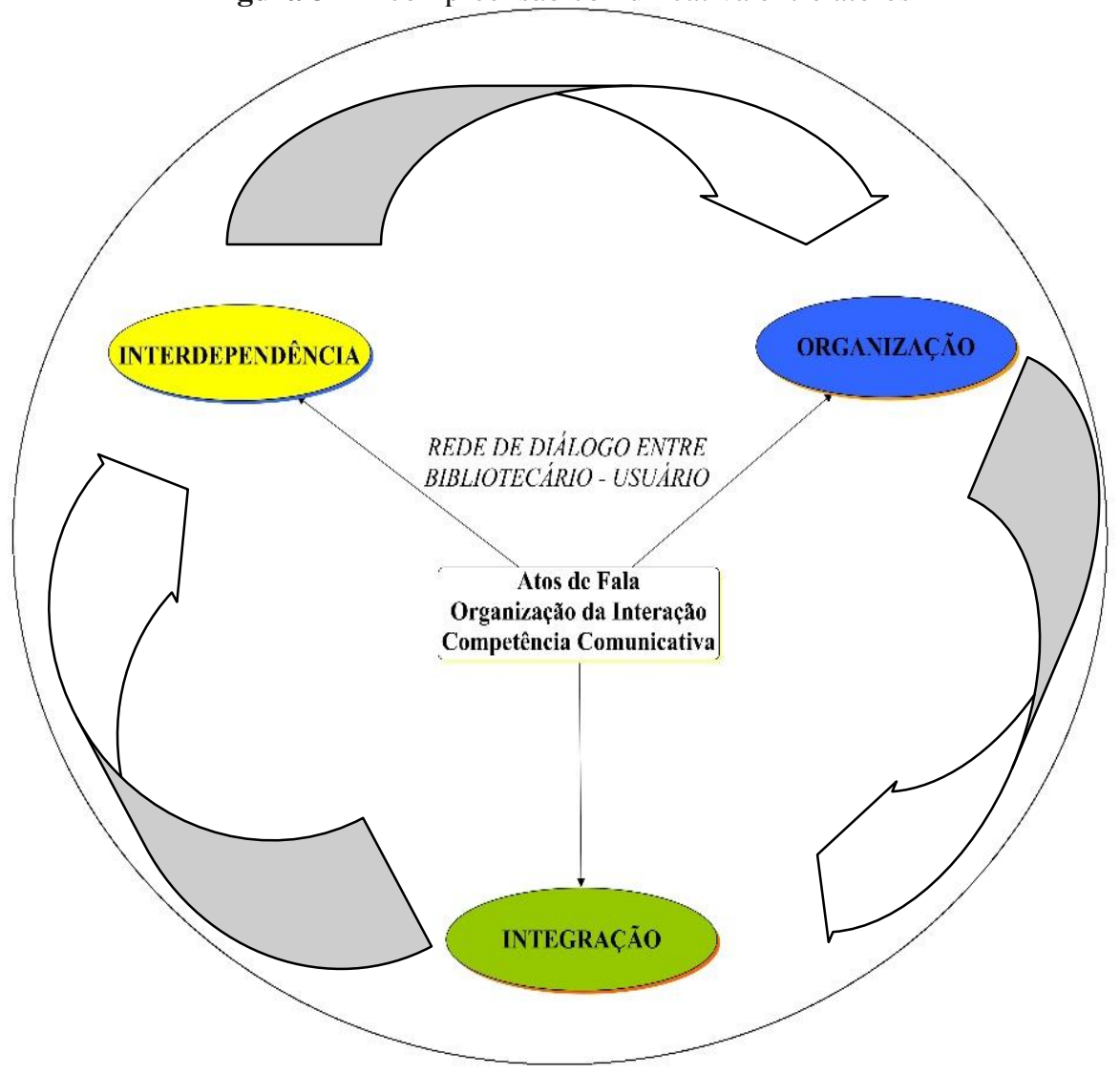

Fonte: Adaptada de Lima e Rivera (2009).

A interação entre bibliotecário - usuário na relação comunicativa tem um viés de redes, em que os sujeitos para construírem um diálogo devem ter autonomia nos atos de mediação expressas por Lima e Rivera (2009) como

\section{Interdependência, Coordenação e Integração.}

- Interdependência: caracteriza a função das relações entre Bibliotecário - Usuários;

- Coordenação: amplia e melhora a comunicação, reduzindo as incertezas para evitar conflitos. (Embora os conflitos sejam parte inerente a qualquer organização social);

- Integração: constitui o processo discursivo mediado pela linguagem e que consiste na autonomia dos sujeitos (bibliotecário usuário) permitindo-lhes atos de cooperação para a realização de ação coletivo emancipatória. 
Como pode ser visto a ideia de rede conforme Lima e Rivera (2009) se deve a interação do conjunto de retalhos que se interligam por meio do diálogo, através da conversação, competência comunicativa e os atos de fala nelas implicados, tornam-se componentes das ações comunicativas entre bibliotecário - usuário (centro do quadro - análise).

No entanto, é importante reiterarmos que a rede de diálogo é uma açãomediada pelos atores bibliotecário - usuário. Essa integração se dá por meio das relações não “[...] hierárquicas e interdependentes, incluindo gestores, profissionais e usuários mediante a conversação para concretizar seus diversos interesses e promover a integração dos serviços.” (LIMA; RIVERA, 2009, idem.).

Com isso, a rede de diálogo percorre o modelo de sistema informacional aberto, que se dissocia da ação instrumental (técnica) de regras e normas, que enfraquecem as práticas mediadoras. Nesse contexto, na rede de diálogo os atos de mediação entre bibliotecários e os usuários se entrecruzam e reformam o fluxo de informações. Um outro aspecto abordado de acordo com Lima e Rivera (2009) está na ideia de fazer uma intensa rede de conversa e análise e, consequentemente, uma possível maneira de entender o diálogo na rede informacional.

Tendo em vista esses aspectos, a rede de diálogo entre bibliotecária usuário vincula-se da ação comunicativa dos sujeitos na biblioteca, uma vez que, esse agir é orientado para o entendimento "[...] mútuo entre os atores, além de esboçar os conceitos conexos do mundo social e do agir regulado por normas que resultam do descentramento da compreensão do mundo." (HABERMAS, 1989, p. 164). Que de acordo com Habermas (1989) é agenciada na construção de acordos, consenso e construída sobre interações coletivas, e não de eventos ou até mesmo de influxos externos entre os sujeitos.

À vista disso, a contextualização sobre a Mediação da Informação na atividade bibliotecária existe pela tangência da própria ideologia da técnica da ciência moderna, em razão de, no contexto profissional essa racionalidade ter sido intensificada nos processos normativos de descrição e representação das fontes informacionais, não havendo de forma alguma emancipação no sentido de 
que enxergar à informação “[...] cada vez mais, um elemento de inclusão social, trazendo desenvolvimento para as pessoas e nações." (FREIRE, 2007, p. 16).

\section{Considerações finais}

A pesquisa contribuiu para entendermos, de forma teórica e interpretativa, a importância da Mediação da Informação como ação de libertação coletiva na prática dos bibliotecários. Com a tentativa de proporcionar um espaço discussão de questões que intrigam as práticas de mediação. Para isso, foi necessário levantar o debate e mostrar a relevância teórica, para um melhor entendimento desse fenômeno na qual se tornou imprescindível neste estudo.

Ao longo da pesquisa, foram estudados aspectos da mediação, ação técnica e ação emancipatória na qual, entendeu-se a necessidade de conduzir os profissionais bibliotecários a se aproximarem mais do social, por meio da mediação e de práticas discursivas com o objetivo de construir aportes para pensar a além da técnica.

De igual modo, estamos convencidos que a racionalidade instrumental (técnica) enfraquece a mediação nas atividades bibliotecárias, deixando-as engessada pelo condicionamento de sua objetividade. Mas por meio da ação coletiva emancipatória há a superação desse paradigma. Portanto, situamos que o processo de mediação acontecerá na emancipação e não na tecnicidade com seus regimes.

Os resultados indicam que, a Mediação da Informação nas atividades que envolvem a prática bibliotecária é dominada pela racionalidade instrumental da técnica e, por sua vez, é necessário o processo emancipatório para desestruturar a dependência do bibliotecário - usuário no sistema, uma vez que, por esse ângulo, a mediação se dará no agir comunicativo de uma atividade informacional, melhor dizendo, na intersubjetividade dos sujeitos.

Conclui-se que o problema da mediação na prática bibliotecária constitui-se pela falta do pensar crítico a partir do "confinamento de regras" que o deixa preso na dependência de normas, procedimentos técnicos dominantes de representação da informação e dependentes de um sistema estrutural balizada pelo aspecto da herança da razão instrumental. 
Por esse motivo, considera-se, que a Mediação da Informação na prática bibliotecária necessita de questionamentos teóricos, de modo que possa se consolidar com um olhar crítico, produzindo "novas" relações possíveis de debate em torno do seu núcleo teórico-prático, de maneira que as ações comunicativas possam superar elos políticos fundados na razão instrumental (ideologia da técnica), vindo a considerar uma abordagem relacional, principalmente, na produção de ações coletivas emancipatórias no ambiente das bibliotecas e, por fim, práticas que ressignificam a mediação.

\section{Referências}

ALMEIDA JÚNIOR, O. F. de. Mediação da informação e múltiplas linguagens. Pesquisa Brasileira em Ciência da Informação, Brasília, v.2, n.1, p.89-103, jan./dez. 2009.

ALMEIDA JÚNIOR, O. F. de. Conservadorismo e revolução (ou reformismo) na Biblioteconomia e na ciência da informação. Divers@! Revista Eletrônica Interdisciplinar, v. 8, n. 2, 2015.

ALMEIDA, M. A. de. Mediações da cultura e da informação: perspectivas sociais, políticas e epistemológicas. Tendências da Pesquisa Brasileira em Ciência da Informação, v. 1, n. 1, p. 1-24, 2008. Disponível em: http://inseer.ibict.br/ancib/index.php/tpbci/article/view/6/12. Acesso em: 19 mar. 2018.

ALMEIDA, M. A. de. A produção social do conhecimento na sociedade da informação. Informação \& Sociedade. Estudos, João Pessoa, v. 19, n. 1, p. 11- 18, 2009.

ARAÚJO, C. A. A. Correntes teóricas da ciência da informação. Ciência da Informação, v. 38, n. 3, p. 192-204, 2009.

ARAÚJO, E. A. de. Transferência de informação como processo social: uma proposta de paradigma. Informação \& Sociedade: Estudos, João Pessoa, v. 7, n. 1, 1997. Disponível em:

http://www.ies.ufpb.br/ojs/index.php/ies/article/view/358/1605. Acesso em: 24 set. 2018.

DAVALON, J. La médiation: la communication en process.

Médiations\&Médiateurs, Paris, n.19, p.37-59, 2003. Tradução de Maria Rosário Saraiva. Revisão de Maria Rosário Saraiva e Helena Santos. 
GONZÁLEZ DE GOMEZ, M. N. A representação do conhecimento e o conhecimento da representação: algumas questões epistemológicas. Ciência da Informação, v.22, n.3, p.217 - 222, set. / dez. 1993.

GONZÁLEZ DE GOMEZ, M. N. Regime de informação: construção de um conceito. Informação \& Sociedade: Estudos, v. 22, n. 3, 2012.

HABERMAS, J. A crise de legitimação no capitalismo tardio. Rio de Janeiro: Tempo Brasileiro, 1980.

HABERMAS, J. Conhecimento e interesse. Rio de Janeiro: Zahar, 1987.

HABERMAS, J. Consciência moral e agir comunicativo. Rio de Janeiro: Tempo Brasileiro, 1989.

HABERMAS, J. O Discurso filosófico da modernidade. 2. ed. Lisboa: Publicações Dom Quixote, 1998.

HABERMAS, J. Teoría de la acción comunicativa I: Racionalidad de la acción y racionalización social. Madrid: Taurus, 1999.

HABERMAS, J. Agir comunicativo e razão destranscendentalizada. Rio de Janeiro: Tempo Brasileiro, 2002.

HABERMAS, J. Técnica e Ciência como “ideologia”. Lisboa: Edições 70, 2009.

LIMA, J. de C.; RIVERA, F. J. U. Agir comunicativo, redes de conversação e coordenação em serviços de saúde: uma perspectiva teórico-metodológica. Interface - Comunic., Saude, Educ., v.13, n.31, p.329-42, 2009. Disponível em: http://www.scielo.br/scielo.php?script=sci_arttext\&pid=S141432832009000400008. Acesso em: 5 out. 2018.

SARTRE, J. P. O ser e o nada: Ensaio de ontologia fenomenológica. Tradução de Paulo Perdigão. Petrópolis, RJ: Vozes, 2011.

SESSA, P. da S. A construção de significados e as ferramentas culturais em atividades de campo: demanda para o ensino de Biologia. 2013. $210 \mathrm{f}$. Tese (Doutorado em educação) - Universidade de São Paulo, São Paulo, 2013.

SILVA. L. E. F. da. Ciência como técnica ou técnica como ciência: nas trilhas da Arquivologia e seu status de cientificidade. 2013. 138 f. Dissertação (Mestrado em Ciência da Informação) - Universidade Federal da Paraíba, João Pessoa, 2013.

KOCHE, J. C. Fundamentos de metodologia científica: Teoria da Ciência e iniciação à pesquisa. Petrópolis, RJ: Vozes, 1997. 
FREIRE, Gustavo Henrique de Araújo. Ciência da Informação: temática, histórias e fundamentos. Perspectivas em Ciência da Informação, [S.1.], v. 11, n. 1, nov. 2007. ISSN 19815344. Disponível em:

http://portaldeperiodicos.eci.ufmg.br/index.php/pci/article/view/442. Acesso em: 27 dez. 2018.

\title{
The importance of mediating communicative information in library practice
}

\begin{abstract}
Since communication actions allow relational practices that go beyond knowledge transfer in librarian activities, the objective is to analyse the importance of information mediation as collective liberation action in the practice of librarians. For this, a theoretical study was sought, the development of which was based on the idea of communicative action by Jurgen Habermas, starting from self-reflection. Thus, in the practice of librarianship, the mediation of information prevails in the instrumental rationality of the technique and, for this reason, must therefore go through the plan of communicative and emancipated actions. Although the subject studied is explored in the literature, it should be considered that its theoretical and practical foundations have not yet been critically projected, especially when evaluating the "new" discussion relationships in Their environment and the new sense of library practices.
\end{abstract}

Keywords: Communicative Action. Instrumental Ratio. Emancipation. Mediation. Librarian.

Recebido: 03/03/2019

Aceito: 16/07/2019

\footnotetext{
${ }^{1} \mathrm{O}$ enquadramento metodológico que estabelece o sentido da validade desta categoria de enunciados críticos avalia-se pelo conceito da auto-reflexão. Esta liberta o sujeito da dependência de poderes hipostasiados. A auto-reflexão está determinada por um interesse emancipatório do conhecimento. As ciências de orientação crítica partilham-no com a filosofia. (HABERMAS, 2009, p. 140).

${ }^{2}$ Uma ação mediada se desenvolve à medida que o agente vai aprendendo a utilizar a ferramenta cultural escolhida, ou seja, se o agente for hábil na sua utilização. Isto significa que para uma ação mediada desenvolver-se há necessidade da adequação entre a relação 'agente utilizando uma ferramenta cultural' e o contexto desta utilização. (SESSA, 2013, p. 39).

3 “[...] relação entre emissor e receptor através da transmissão da informação. Neste modelo um emissor comunica uma mensagem ao um receptor através de um canal. Nesta relação, a
} 
informação é vista de forma linear e mecanizada; o que não representa a realidade do processo de comunicação" (ARAÚJO, 1997, p. 69).

${ }^{4}$ A teoria do agir comunicativo de Habermas (1987) tem manifestado a sua produtividade teórica para a tematização da mediação, principalmente quando a compreendemos no sentido de um processo formativo que pode, na perspectiva do consenso, contribuir para a formação da competência comunicativa dos profissionais da informação.

5 Regime de Informação remete às relações informação-poder, relações que hoje estariam alavancadas pela pressuposição de que a informação, como algo imerso nas tecnologias digitais e ubíquas, seria aquilo que nelas circula e as dinamiza. (GONZÁLEZ DE GOMEZ, 2012, p. 44). 